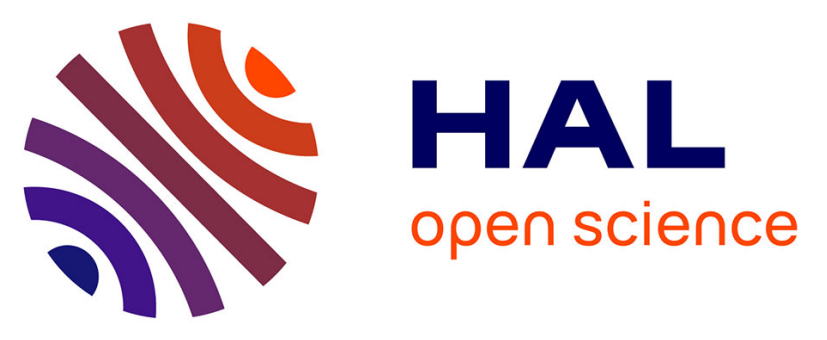

\title{
Nocturnal temperature changes over Tropics during CAWSES -III campaign: Comparison with numerical models and satellite data
}

U. Jaya Prakash Raju, Philippe Keckhut, Yann Courcoux, Marion Marchand, Slimane Bekki, Béatrice Morel, Hassan Bencherif, Alain Hauchecorne

\section{To cite this version:}

U. Jaya Prakash Raju, Philippe Keckhut, Yann Courcoux, Marion Marchand, Slimane Bekki, et al.. Nocturnal temperature changes over Tropics during CAWSES -III campaign: Comparison with numerical models and satellite data. Journal of Atmospheric and Solar-Terrestrial Physics, 2010, 72 (16), pp.1171-1179. 10.1016/j.jastp.2010.07.013 . hal-00509028

\section{HAL Id: hal-00509028 \\ https://hal.science/hal-00509028}

Submitted on 25 Oct 2016

HAL is a multi-disciplinary open access archive for the deposit and dissemination of scientific research documents, whether they are published or not. The documents may come from teaching and research institutions in France or abroad, or from public or private research centers.
L'archive ouverte pluridisciplinaire HAL, est destinée au dépôt et à la diffusion de documents scientifiques de niveau recherche, publiés ou non, émanant des établissements d'enseignement et de recherche français ou étrangers, des laboratoires publics ou privés. 


\title{
Nocturnal temperature changes over tropics during CAWSES-III campaign: Comparison with numerical models and satellite data
}

\author{
U. Jaya Prakash Raju ${ }^{a}$, P. Keckhut ${ }^{\text {a,*, }}$ Y. Courcoux ${ }^{\text {b }}$, M. Marchand ${ }^{\text {a }}$, S. Bekki ${ }^{\text {a }}$, B. Morel ${ }^{\text {b }}$, \\ H. Bencherif ${ }^{b}, A$. Hauchecorne ${ }^{a}$

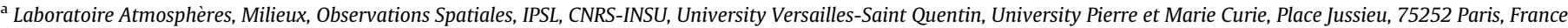

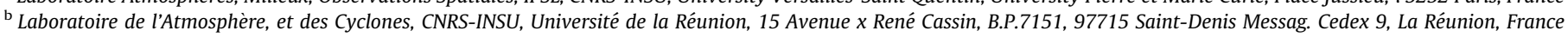

\begin{abstract}
A B S T R A C T
In the frame of the third CAWSES tidal campaign in June-August 2007, lidar and satellite data were collected and compared with numerical models. Continuous nocturnal middle atmospheric temperature measurements performed with a Rayleigh lidar located at La Reunion Island $\left(20.8^{\circ} \mathrm{S}-55.5^{\circ} \mathrm{E}\right)$ were obtained for three subsequent nights. The results clearly show the presence of tidal components with a downward phase propagation. Comparisons with SABER satellite data show good agreement on tidal amplitude; however, some differences on the structures are reported probably due to the zonal nature of the retrieval provided by the SABER data. The observed tidal components are compared with two different numerical models such as the 2D global scale wave model and the 3D-GCM LMDz-REPROBUS. Both models reveal good agreement with temperature lidar patterns, while simulated tidal amplitudes are smaller by a factor of around $2-2.5 \mathrm{~K}$.
\end{abstract}

\section{Introduction}

The global temperature, density and wind fields induced by the daily cyclic absorption of solar energy in the atmosphere are referred to as solar thermal tides. It is known, theoretically, that the effect of longitudinal variation in the distribution of insolation absorption produces not only a component following the Sun (migrating mode or Sun-synchronous mode) but also other components that do not move synchronously with the Sun (Forbes, 1995; Miyahara and Miyoshi, 1997). Tropospheric water vapor has significant longitudinal variations, which could create possible excitation of nonmigrating modes as Sun-asynchronous modes (Hagan and Forbes, 2003). Migrating tides, which are waves travelling sun-synchronously westward, are forced in the troposphere as well as in the stratosphere and are able to propagate vertically up to the mesosphere and lower thermosphere (MLT). Tidal theories and consequently linear tidal propagation models have been extensively developed (e.g., Chapman and Lindzen, 1970; Forbes, 1982; Hagan et al., 1995). Linear propagation models take into account the zonal-mean zonal background wind and temperature as a function of latitude

\footnotetext{
* Correspondence to: Laboratoire Atmosphères, Milieux, Observations Spatiale (LATMOS: UMR8190), BP 3, 91371 Verrières-le-Buisson, France.

Tel.: +331644743 11; fax: +33169202999.

E-mail address: Keckhut@latmos.ipsl.fr (P. Keckhut).
}

and height. Furthermore, it is a common weakness of linear models that they are not able to describe the tidal variability resulting from internal interactions of different nonlinear wave processes.

General circulation models (GCMs) describe the nonlinear interactions between mean fields, planetary waves and tides. This is quite important as background fields have non-negligible effects (Morel et al., 2004). GCMs extending from the troposphere and stratosphere up to the MLT (e.g., Hamilton, 1995; Miyahara and Miyoshi, 1997; Volodin and Schmitz, 2001) offer the possibility to study the tidal oscillations and their dependence on nonlinear processes and nonmigrating components of tidal forcings. Several numerical models have reported specific simulations on the tidal waves (e.g., Grieger et al., 2002, 2004; Miyahara and Miyoshi, 1997). The global-scale wave model (GSWM) (Hagan et al., 1995, 1999; Hagan and Forbes, 2003) solves the linearized tidal equations, given the frequency, zonal wave number and excitation of a particular oscillation and a specification of the zonally averaged atmospheric state, for the calculation of the global atmospheric tidal response.

Following the Geophysical Fluid Dynamics Laboratory (GFDL) "SKYHI" GCM most research groups involved in climate simulation have included the middle atmosphere in their GCMs (Hamilton et al., 1995; Rind et al., 1988; Butchart and Austin, 1998). The motivation behind these developments is the simulation of the chemical climate, the middle atmosphere being a region where 
dynamics, chemistry and radiation play comparable roles and interact strongly with each other (Andrews et al., 1987). GCMs with a focus on the middle atmosphere have been developed, and changes have also been made by Austin and Butchart (2003). Some of the new and updated GCMs have been tested and compared to observations (Egorova et al., 2005; Steinbrecht et al., 2006). To interpret and assess the capabilities and limitations of these models it is required to determine tides and their dissipation. These comparisons can inform about limitations of the numerous modeled mechanisms involved in tide generation and propagation: radiation, composition and dynamic and coupling mechanisms. Also the validation of these numerical models on the scale of tides is required because similar models are planned to be used for satellite data assimilation on similar time scales. Till now few observations of tides were available. Tidal amplitude and phases from wind measurements using ground based radar covering heights between 70 and $100 \mathrm{~km}$ have been intensively investigated (e.g., Manson et al., 1988; Tsuda et al., 1988; Vincent et al., 1988). However with rocket measurements of wind and temperature between 30 and $60 \mathrm{~km}$, tidal effects were observed with good success (Hoxit and Henry, 1973; Reed, 1972), even though rocket data have limitations such as their poor temporal coverage (sparse coverage of the full day), and were subjected to errors induced by radiation from exposed components of the rockets on the sensors (Hoxit and Henry, 1973) that induced superimposed artificial instrumental tides. Atmospheric tides from satellite measurements have been obtained from LIMS (limb infrared monitor of the stratosphere) instrument aboard the Nimbus7 (Hitchman and Leovy, 1985), from ISAMS (improved stratospheric and mesospheric sounder) and MLS (microwave limb sounder) instruments aboard the upper atmosphere research satellite (Dudhia et al., 1993; Keckhut et al., 1996), and more recently from CRISTA mission (Ward et al., 1999; Oberheide and Gusev, 2002). However, satellite radiometers need systematic validations and periodic calibrations by ground references and observations are impeded with low horizontal and vertical resolutions and a viewing window that limits the local time of observation. In contrast, ground based Rayleigh lidar instruments provide quasi-continuous measurements, with a high resolution in both time and space (Gille et al., 1991). However, the lidar measurements are limited to night-time and clear-sky conditions, and tides need to be studied over several nights using appropriate methods (Morel et al., 2002) to remove the other sources of variability like the gravity wave propagation. Previous observations of tides using lidar temperatures were already preformed (Gille et al., 1991; Dao et al., 1995; Meriwether et al., 1998; Leblanc et al., 1999a, b; Keckhut et al., 1996, 2001; Morel et al., 2002). In this present study, additional observations were performed with a specific focus on the comparison with models in the frame of an international effort.

CAWSES (Climate and Weather of the SunEarth System) is an international program sponsored by SCOSTEP (Scientific Committee on Solar-Terrestrial Physics) focused on the space environment and its impact on life and society. In this framework, a particular emphasis on vertical coupling mechanisms is addressed. Within this program, coordinated campaigns on tides are organized to study their characteristics from the troposphere to the thermosphere. During the first CAWSES tidal campaign, Haefele et al. (2008) investigated daily variations in middle atmospheric water vapor and ozone from two ground-based microwave radiometers located in the Alpine region of Europe and temperature data were obtained from a lidar located near Observatory of Haute-Provence (OHP), and from the SABER experiment (sounding of the atmosphere using broadband emission radiometry) on the TIMED satellite (thermosphere ionosphere mesosphere energetics and dynamics). During the third CAWSES tidal campaign in June-August 2007, the lidar at Reunion Island operated and provided further studies at tropical latitudes.
The aim of this paper is to delineate middle atmospheric mean nocturnal variations averaged from three nights of lidar measurements during the CAWSES tidal campaign period of June 2007 and provide comparisons with different numerical models.

After a brief description of the instrument, data analysis of the mean nocturnal evolution of the temperature deviations is explained. Further we compare our results with recent observations obtained over tropics and from SABER satellite observations and with numerical simulations from GSWM and LMDz model outputs interpolated for the location of La Réunion University where lidar measurements were performed.

\section{Lidar system and data analysis description}

The observations used in this work are obtained from a Rayleigh lidar located at the University of La Réunion, in the north of the island $\left(20.8^{\circ} \mathrm{S}, 55.5^{\circ} \mathrm{E}\right)$. The system has operated since 1993 in the framework of the network for detection of atmospheric composition changes (NDACC) (Baray et al., 2006). It is equipped with a new Nd:YAG laser source that emits $800 \mathrm{~mJ}$ light pulses of $10 \mathrm{~ns}$ duration and $532 \mathrm{~nm}$ wavelength upwards into the atmosphere. The characteristics of the lidar system are summarized in Table 1.The two Rayleigh channels used to derive temperature have not changed since 1995. Backscattered photons are collected by a telescope with a mozaic of 4 mirrors corresponding to a total area of $0.67 \mathrm{~m}^{2}$. By assuming that the atmosphere is an ideal gas in hydrostatic equilibrium and free of aerosols, vertical temperature profiles can then be computed. According to the vertical resolution and the integration time used, hydrostatic equilibrium can be assumed (Jekins and Watts, 1969). Moreover comparisons between lidar and other techniques give a good confidence of the Rayleigh lidar technique, despite the top of the stratospheric aerosol layer not always being perfectly defined and some sporadic layers can be seen above $30 \mathrm{~km}$. The COSPAR International Reference Atmosphere standard model is used for the initialisation of pressure at the top level. CIRA 72 was used initially (Hauchecorne and Chanin, 1980), and then temperature profiles were reprocessed (Keckhut et al., 1993) with successive improved versions as CIRA 86, which includes latitudinal dependence and now the MSIS series including analytical functions instead of data extrapolations (Hedin, 1991). Both

Table 1

$\begin{array}{ll}\text { Emission } & \\ \text { Laser } & \mathrm{Nd}: \mathrm{YAG} \\ \text { Emission wavelength } & 532 \mathrm{~nm} \\ \text { Emission rate } & 10 \mathrm{~Hz} \\ \text { Energy per pulse } & 800 \mathrm{~mJ} \\ \text { Beam divergence } & 0.5 \mathrm{mrad} \\ \text { Bean expander } & \times 20\end{array}$

Reception

Number of optical channels 2

Number of mirrors for channel 1

Diameter of the mirrors

Focal distance of the mirrors

Diameter of the optical fibres

Number of mirrors for channel 2

Diameter of the mirrors

Focal distance of the mirrors

Diameter of the optical fibres

$400 \mathrm{~mm}$

$1.5 \mathrm{~m}$

$0.4 \mathrm{~mm}$

1

$250 \mathrm{~mm}$

$1 \mathrm{~m}$

$1 \mathrm{~mm}$

Detection

Detection mode

Initial vertical resolution

Photon counting

$150 \mathrm{~m}$ 
models are based on the same data and give very similar temperature profiles in the initialisation altitude region.

The top-side pressure required for the temperature analysis is selected from the MSIS climatological model for each hourly profile. We expect the tides at the top to be damped by initialisation at the top of the pressure profiles while the same initialisation value is used. However, as soon as we drop in altitude, the uncertainty in the pressure profile due to the initialisation rapidly becomes negligible because of the exponential decrease in the atmospheric pressure. Assuming that pressure varies with height as

$p=p_{M}\left(z_{\text {top }}\right) \exp \left(\frac{z-z_{\text {top }}}{H}\right)$

where $H$ is a mean scale height, we can consider that the temperature uncertainties induced by the model are reduced by $15 \%$ at two scale heights below the starting altitude. The initialisation is performed around $90-100 \mathrm{~km}$ and then below $75 \mathrm{~km}$ the temperature profile is not influenced by initialisation and tidal amplitudes unbiased.

As lidar measurements are limited by cloud cover and sunlight, the lidar system can be operated only during nights with clearweather conditions and continuous lidar series are difficult to collect. However during this specific campaign, the lidar data were obtained continuously for three nights from June 20 to 22 ,
2007 (" 12 h" per night). A total of approximately $36 \mathrm{~h}$ of data roughly from 18:00 to 05:00 local solar time (LST) were available.

It is difficult, from a single night of measurement, to clearly identify the tidal signature: due mainly to the presence of longperiod gravity waves and nonmigrating tidal modes, which can be generated by local topography and latent heat release. As suggested by Leblanc et al. (1999a), to reduce this geophysical noise obscuring the tidal signatures, the lidar retrieval of temperature can be reduced by averaging several nights of measurements at given LST to obtain mean temperature profiles as a function of LST. Thus integration process reduces most of the noise from geophysical origins, specifically gravity waves, which are expected to be random according to LST from one night to another, but also instrumental noise that increases with altitude (see Fig. 1).

When the series of measurements do not exhibit different time lengths, the average of anomalies is made complex by the estimate of the mean-of-the-night that cannot be done similarly because the available time length is different. A method has been developed by Morel et al. (2002) to adjust the nocturnal mean during each night. However, for the observations used here, the three successive nights are similar and anomalies can be averaged without introducing bias. Hence, the initial 3-min raw data records were combined to form 1 -h long records centered on each successive hour, with 150 -m vertical resolution. The hourly mean

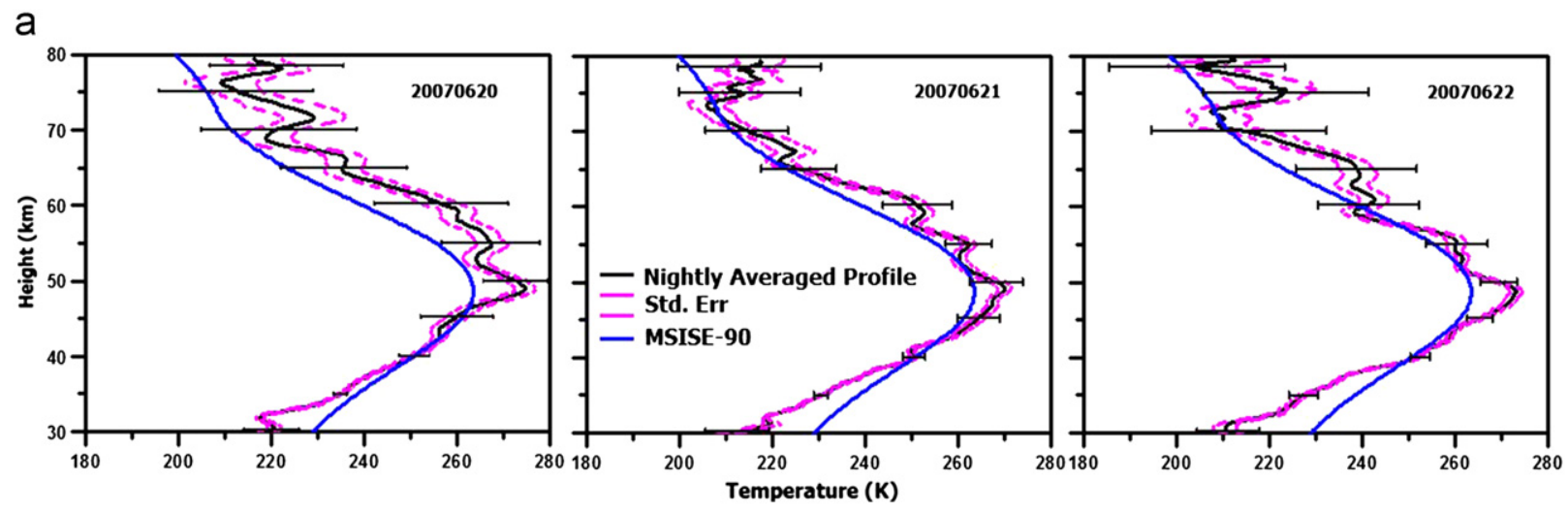

b

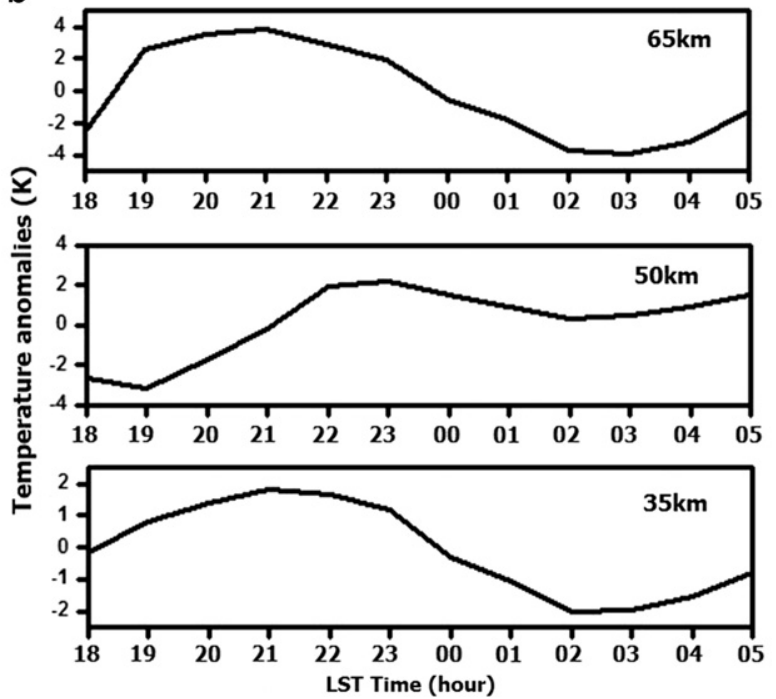

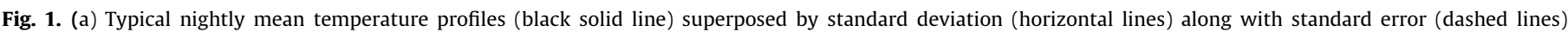

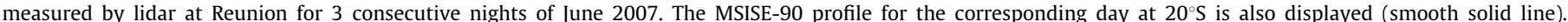
(b) Nocturnal evolution of the temperature anomaly between 7 p.m. and 5 a.m. at three heights 35,50 and $65 \mathrm{~km}$, respectively. 
temperature profiles were subtracted from the background mean temperature. During the night, in addition to tides, low frequency changes may exist. Those trends were estimated by interpolation from successive nightly averaged profile and subtracted from each individual nightly hourly series. Finally all the 1 -h temperature anomalies for the three successive nights were averaged according to LST to obtain mean profiles at given LST (hereafter called as averaged temperature differences (ATD)).

\section{Nocturnal evolution of the temperature: comparison with SABER}

Fig. 1(a) shows the evaluation of the nightly mean temperature profiles obtained by lidar for 3 consecutive nights superposed by standard deviation. The MSISE-90 profiles for the corresponding days are shown by smooth solid line. Although the temperature profiles for three days look similar below $50 \mathrm{~km}$ with constant magnitude, above this altitude larger fluctuations of about 20$30 \mathrm{~K}$ are observed. A very weak mesospheric temperature inversion layer was observed between 70 and $80 \mathrm{~km}$ altitude. Mesospheric temperature inversions are suggested to be due to the interactions between gravity waves and the mean flow (Hauchecorne and Maillard, 1990). Since tidal vertical wavelengths are about $20 \mathrm{~km}$ or more, short vertical wavelengths (less than $6 \mathrm{~km}$ ) are filtered out using a vertical filter with a $6-\mathrm{km}$ cutoff wavelength. In order to reduce the magnitude of temperature anomalies (statistical noise) due to the decreasing number of available data points with altitude, where the estimated error due to the lidar noise predominates, we applied a 5th order polynomial regression to lidar ATDs at every $5 \mathrm{~km}$ altitude interval. The smoothed appearance of diurnal evolution of temperature in stratosphere and mesosphere is shown in Fig. 1(b).

The temperature differences obtained by lidar every hour between 18:00 and 05:00 are contoured as a function of altitude and time in Fig. 2. The figure shows a characteristic behaviour that suggests the presence of tidal components by its successive warm and cold temperature bands:

- Fig. 2 clearly depicts a well-defined warm period continuously propagating downward from $70 \mathrm{~km}$ at 18:00 LST to $55 \mathrm{~km}$ at
05:00 LST with a vertical wavelength of roughly $25 \mathrm{~km}$ and phase speed of $1.2 \mathrm{~km} / \mathrm{h}$ and surrounded by two colder regions above and below.

- At the lower end of this layer the warm late night is followed by cold early night between 55 and $65 \mathrm{~km}$, which is the result of the downward propagating temperature inversion layer. It is consistent with previous lidar observations at similar latitudes (Leblanc et al., 1999a) and at mid-latitudes (Gille et al., 1991).

- In the upper stratosphere and the lower mesosphere (i.e., roughly between 40 and $50 \mathrm{~km}$ altitude), well defined periods with negative ATD values between 18:00 and 23:00 LST and positive ATD values from 03:00 to 05:00 LST were observed, which differ slightly from the previous results (positive ATD values at early night and negative ATD values at mid night) by Morel et al. (2002) from the same station for the fall equinox period (October/November 1995).

- At and around the stratopause region, temperature perturbations were more pronounced with near-zero ATD values occurring between 00:00 and 02:00 LST.

In addition to large-scale patterns associated with tides, other short-term structures remain probably due to gravity waves.

SABER (sounding of the atmosphere using broadband emission radiometry) instrument mounted on the TIMED satellite sounds the mesosphere and lower thermosphere region of the earth's atmosphere by measuring infrared limb emission. The instrument measures accurate values of atmospheric limb radiances that are ground processed to retrieve temperature, ozone, water vapor, carbon dioxide, and key parameters describing the energetics of the high atmosphere (Mlynczak, 1997). It provides unprecedented geographical coverage for the determination and study of atmospheric tides. A modified method for analysing tides has been given by Zhang et al. (2006). Unfortunately, owing to the slow local time precession rate of the TIMED satellite orbit, 120 days of data are required to cover a full diurnal cycle and thus to derive the tidal fields. SABER model provides the tidal and stationary wave components as well as zonal mean of SABER temperature data for 5 years averaged over 2002-2007 between 20 and $120 \mathrm{~km}$ altitude and $-50^{\circ}$ to $50^{\circ}$ latitude. Tidal components including diurnal, semidiurnal and terdiurnal for 13 zonal wave numbers centered at the migrating ones are provided.

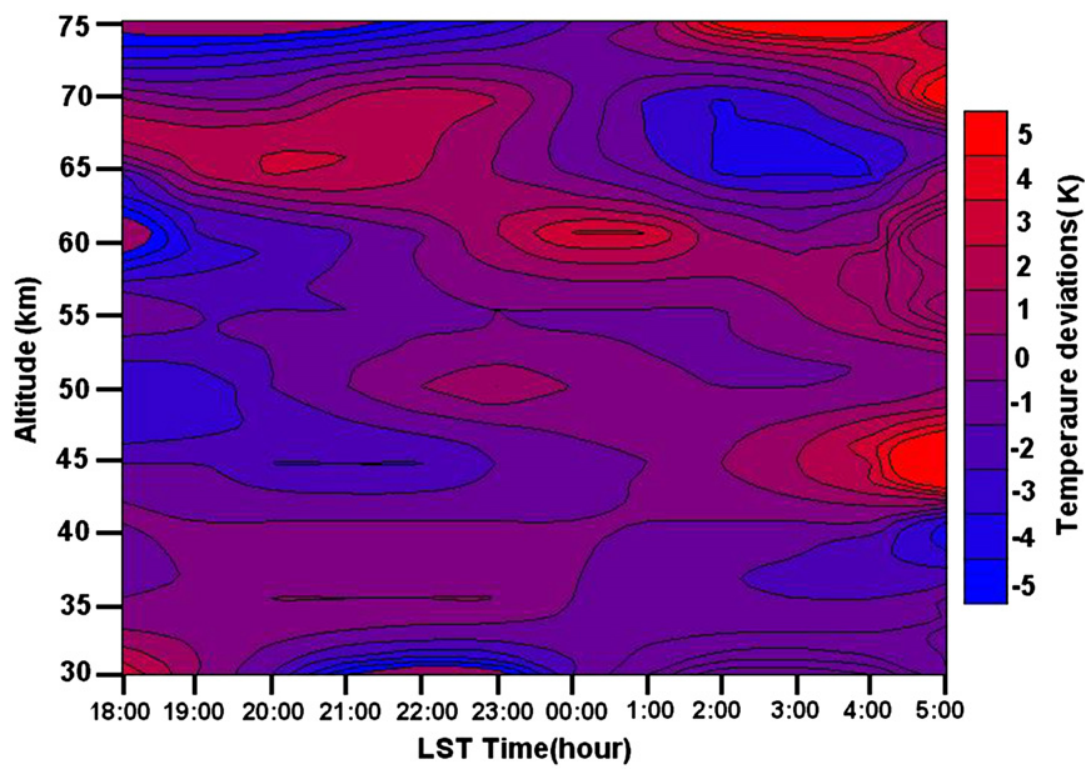

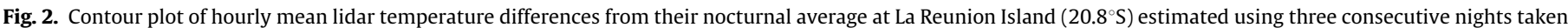
from June 20 to $22,2007$. 


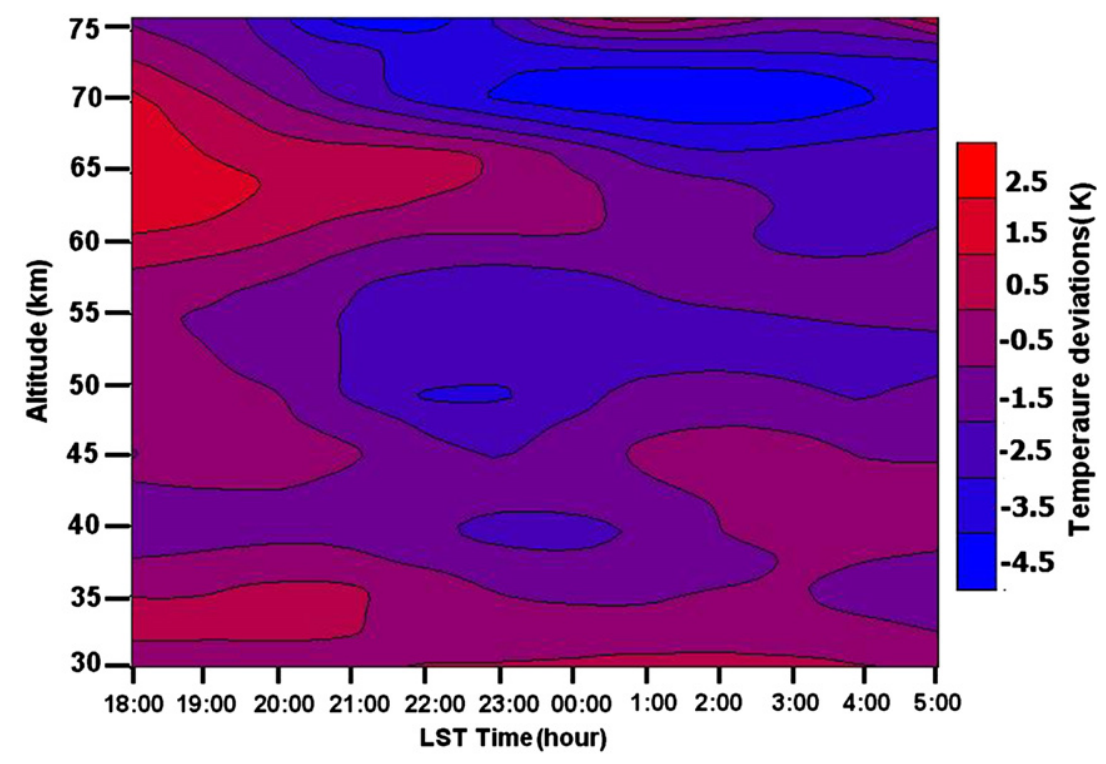

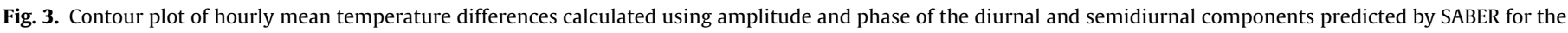
month of June at $21^{\circ} \mathrm{S}$.

The SABER ATD values used in this analysis are interpolated for La Réunion site.

The observed lidar ATD have been compared with the corresponding SABER values calculated from the SABER derived climatological tidal model from Zhang et al. (2006).

Nocturnal SABER temperature changes were calculated by using the diurnal and semidiurnal phases and amplitudes by using the following formulae:

$T(z, t)_{G S W M}=\bar{T}_{0}(z)+A_{24}(z) \cos \left\{\frac{2 \pi}{24}\left[t-\varphi_{24}(z)\right]\right\}+A_{12}(z) \cos \left\{\frac{2 \pi}{12}\left[t-\varphi_{12}(z)\right]\right\}$

where $\overline{T_{0}}$ is the diurnal mean temperature (i.e., 24-h average), $t$ is the local solar time, $z$ is the altitude and $A_{24}(z), A_{12}(z), \varphi_{24}$ and $\varphi_{12}$ are the amplitudes and phases of the diurnal and semidiurnal components given by the SABER model.

The SABER differences from night-time averages are shown in Fig. 3. The magnitude of the SABER ATD values is roughly half of the observed lidar values. SABER observations also show warm periods propagating downward from $70 \mathrm{~km}$ at 18:00 LST to $60 \mathrm{~km}$ at 00:00 LST and surrounded by colder periods above this layer, consistent with lidar observations. Below this layer between 55 and $65 \mathrm{~km}$, a cold anomaly was observed at $50 \mathrm{~km}$ starting at 21:00 while lidar evolution exhibits a warm anomaly that continues over the whole night. In the upper stratosphere at 40-45 km SABER predicts a colder early night and a warmer late night appears to be in agreement with lidar observations between 40 and $50 \mathrm{~km}$. In the $30-35 \mathrm{~km}$ region SABER observed a warm period followed by a colder temperature similar to the lidar observations.

\section{Comparison of lidar observations with numerical models}

Two very different types of numerical models have been used for comparisons. The GSWM (global scale wave model) is a 2-D model developed specifically for tidal investigations, while the LMDz-Reprobus is a 3-D model developed for climate change studies that should in principle include all the processes to produce tidal waves.
The GSWM is a 2-D, linearized, steady-state numerical tidal and planetary wave model that extends from ground to the thermosphere. It has been optimized to provide the thermally forced global tides throughout the atmosphere on a monthly mean basis. The model includes some processes of importance to estimate the global atmospheric tidal response: surface friction, mean winds and meridional gradients in scalar atmospheric parameters, radiative cooling, eddy and molecular diffusion and ion drag. The background wind distributions are based on observational data, and the zonal mean temperatures and densities are specified using an empirical model (Hedin, 1991). GSWM employs the tropospheric tidal heating formulae of Groves (1982), which are based on 3-month averaged global models of specific humidity centered on January, April, July and October. In the stratosphere, throughout the mesosphere, and into the lower thermosphere GSWM tidal heating is based on a parameterization reported by Strobel (1978). We compare the observed ATD to the corresponding values calculated from the outputs of the GSWM00 tidal model (http://www.hao.ucar.edu/modeling/gswm/gswm. html), which is an extension to the GSWM-98 (Hagan et al., 1999). The GSWM ATD values are obtained from the GSWM amplitudes and phases of the diurnal and semidiurnal migrating tides (Fig. 4) It has been found that diurnal and semidiurnal amplitudes observed by SABER differ by at least a factor of 2 with that of GSWM predictions. Moreover, phases of GSWM corresponding to the latitude of $24^{\circ} \mathrm{S}$ clearly coincide with SABER phases. Hence, considering the suggestions by Leblanc et al. (1999b) (GSWM might be imprecise in latitude) and previous reports by Morel et al. (2002), we used GSWM ATD values for the latitude of $24^{\circ} \mathrm{S}$ instead of $21^{\circ} \mathrm{S}$ in our present analysis.

The temperature difference values (ATD) predicted by GSWM for the month of June at the latitude around Reunion $\left(24^{\circ} \mathrm{S}\right)$ are shown in Fig. 5. As reported in previous studies (Dao et al., 1995; Meriwether et al., 1998; Leblanc et al., 1999a, b), the GSWM ATD values are much smaller than the observed values. Remarkable similarities are found between lidar and GSWM results with still strong disagreement. First, the downward propagating warm region, shown in Fig. 2, is also predicted by GSWM. The cold early night and warm late night observed by lidar in the thin layer $55-65 \mathrm{~km}$ are also predicted by GSWM but with much smaller 

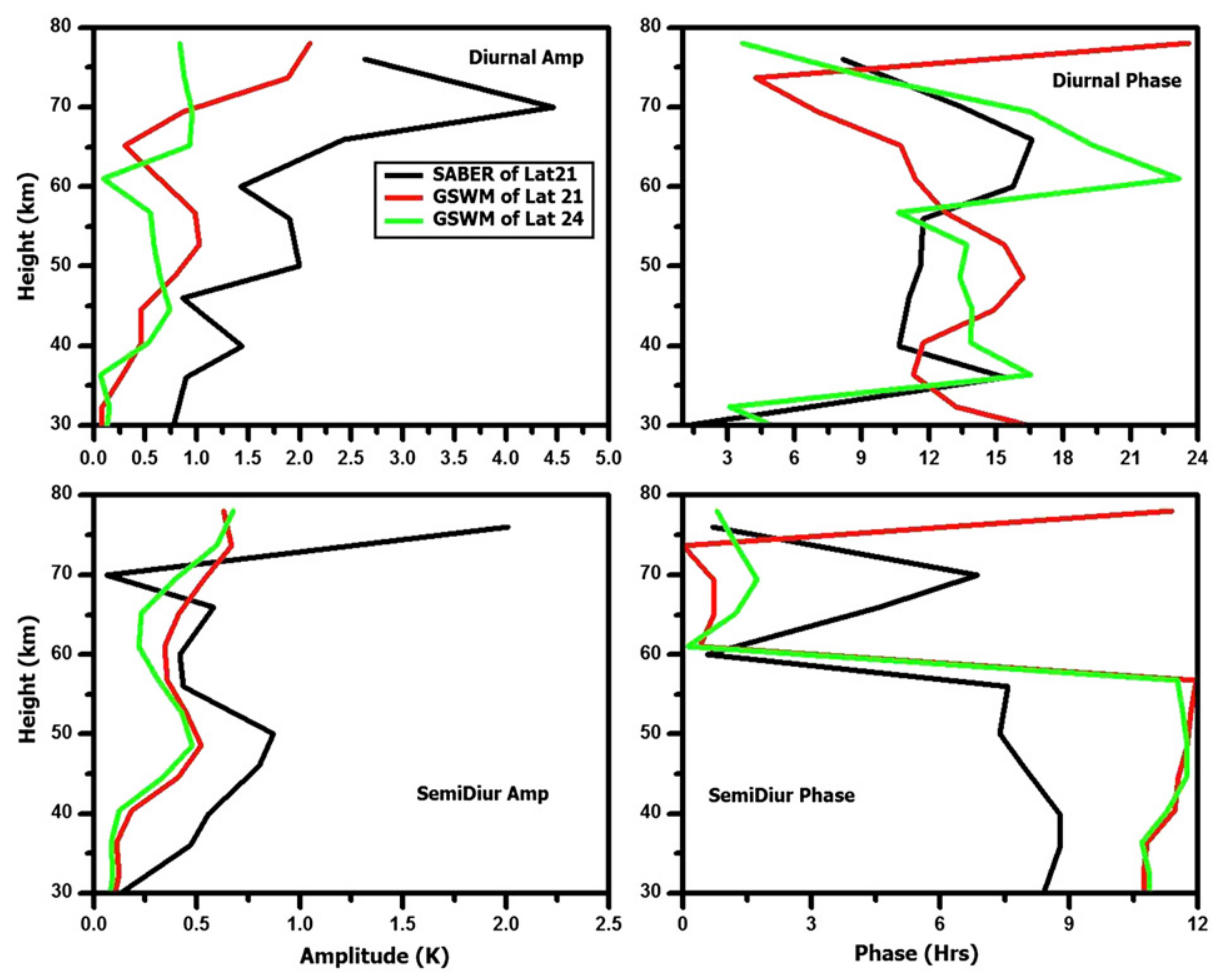

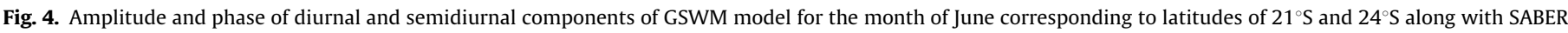
model data for $21^{\circ} \mathrm{S}$.

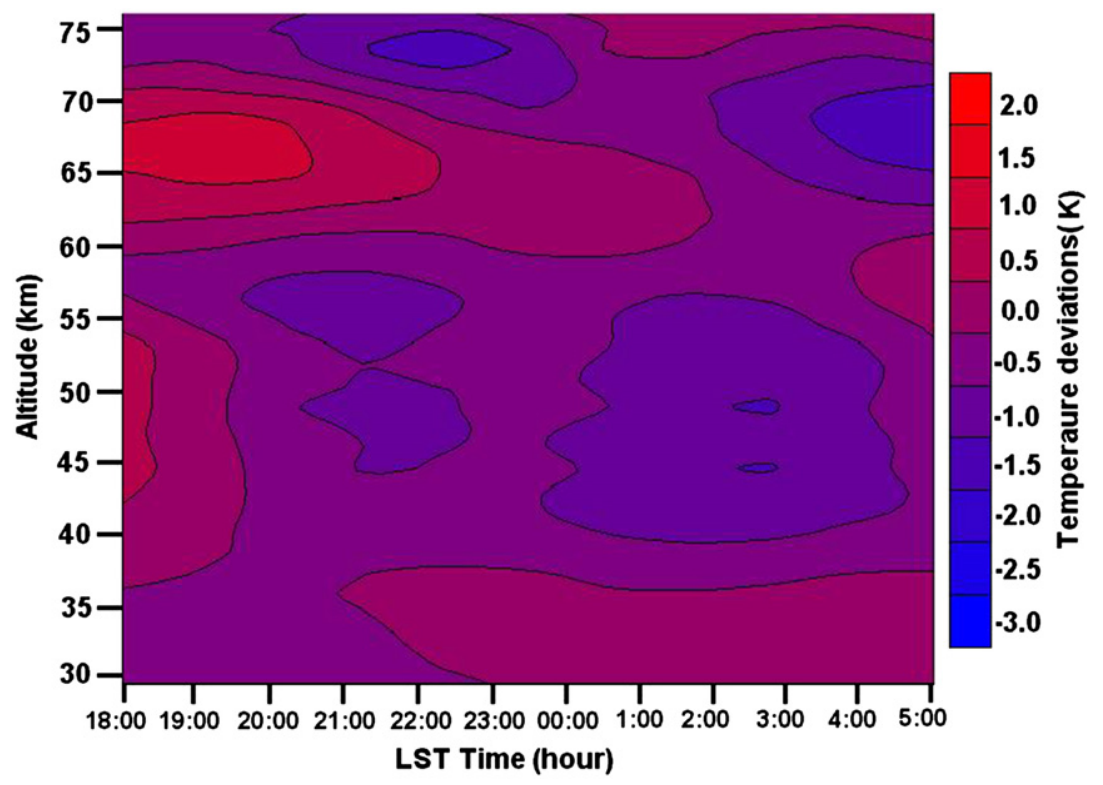

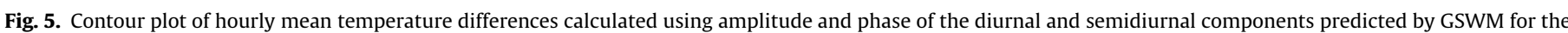
month of June at $24^{\circ} \mathrm{S}$.

amplitudes with $1 \mathrm{~h}$ delay. It indicates that the mesospheric temperature inversions observed above Reunion in June are the result of the combined effect of the diurnal and semidiurnal component. The GSWM simulations exhibit warm early night followed by cold late night in the range $45-55 \mathrm{~km}$. Strong disagreement is also observed in the $30-40 \mathrm{~km}$ range with positive ATD values being seen at the end of the night in the GSWM. The GSWM diurnal and semidiurnal amplitudes and phases for the latitude of $24^{\circ}$ are shown in Fig. 4. The diurnal amplitude exhibits a minimum around $61 \mathrm{~km}$ with a fast phase transition, characteristic of the transition between the upper stratospheric trapped modes and the upward propagating modes. Immediately above the transition layer, the warm late night following the cold early night is the consequence of the growing diurnal amplitude between 60 and $65 \mathrm{~km}$ and was followed by a substantial decrease and by the emergence of the semidiurnal component, resulting in the formation of the mesospheric temperature inversion layers.

LMDz-Reprobus is a fully coupled 3-D chemistry-climate model (CCM) (Eyring et al., 2006), which is one of the components of the IPSL 


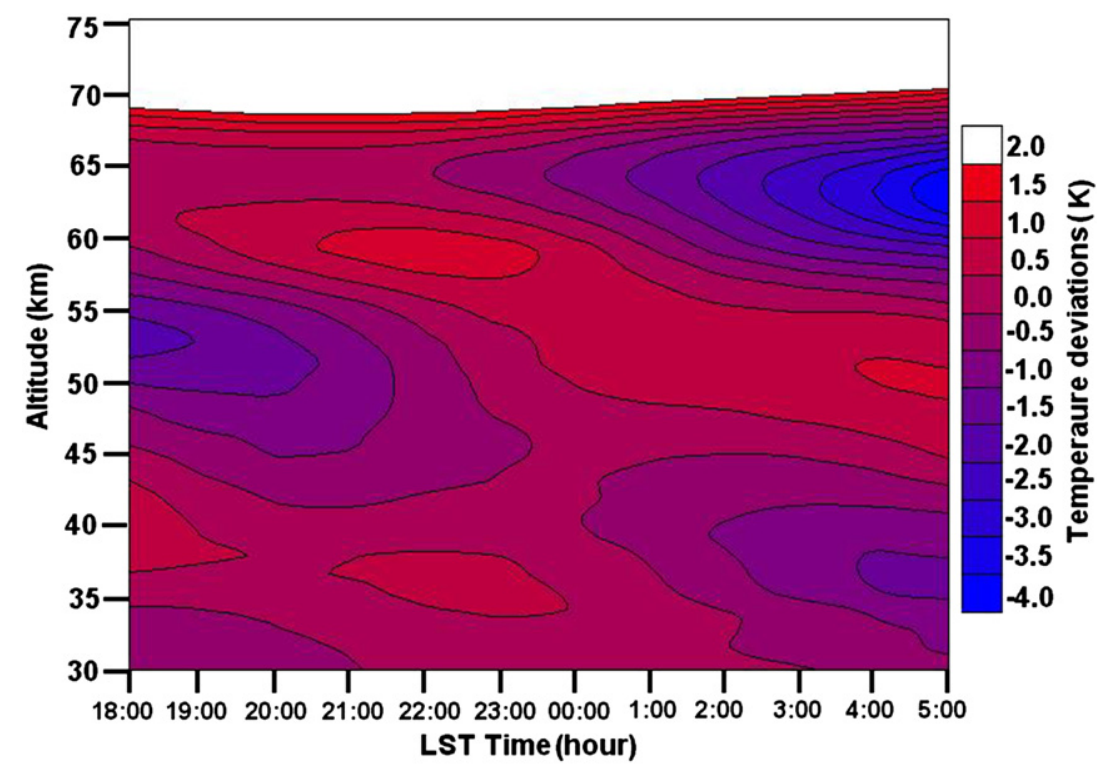

Fig. 6. Contour plot of hourly mean temperature differences calculated from the LMDz model for the month of June at latitude band of $10-30^{\circ} \mathrm{S}$.

earth system model. The dynamical model used is the stratospheric extension of the LMDz fourth generation atmospheric GCM described in Lott et al. (2005). It is a gridpoint model. It currently uses a uniform resolution of $2.5^{\circ}$ in latitude and $3.75^{\circ}$ in longitude. The vertical coordinate is a hybrid sigma pressure. It currently uses 50 levels with the upper level near $65 \mathrm{~km}$. The resolution in the stratosphere varies slowly from $1 \mathrm{~km}$ at $12 \mathrm{~km}$ to $3 \mathrm{~km}$ at $50 \mathrm{~km}$ and reaches $6 \mathrm{~km}$ at the model top. The model is interactively coupled to the module of atmospheric chemistry from the REPROBUS chemistry transport model. The module contains a comprehensive stratospheric chemistry scheme. It describes a large range of chemical reactions associated with species from $\mathrm{O}_{x}, \mathrm{HO}_{x}, \mathrm{ClO}_{x}, \mathrm{BrO}_{x}$ and $\mathrm{NO}_{x}$ families and source gases. The model-calculated fields of radiatively active species such as ozone or $\mathrm{CH}_{4}$ are used as input variables of the radiative routine. Because of this configuration, most CCMs are fully interactive and are probably the most suitable tools to make simulations of the atmospheric composition in a changing climate. In the present analysis, we used the diurnal temperature for the month of June, at the zonally averaged latitude band of $10-30^{\circ} \mathrm{S}$.

Continuous hourly series of temperature profiles, which correspond to an average, are available from the CCM over a full month after the model being in equilibrium from the initialisation. The temperature differences obtained by LMDz for every hour between 18:00 and 05:00 LST are contoured in Fig. 6. The lidar and LMDz observations seem to be in reasonably good agreement with an attitude shift of $5 \mathrm{~km}$ in $\mathrm{LMDz}$ observations. Fig. 5 shows a continuous downward propagation of a warm layer between 67 and $57 \mathrm{~km}$ in lidar, which is also predicted by LMDz output between 62 and $50 \mathrm{~km}$ within this case a vertical wavelength of $25 \mathrm{~km}$ approximately and phase speed of $1 \mathrm{~km} / \mathrm{h}$. Below this structure, a thin layer of warm late night followed by cold early night is observed between 45 and $55 \mathrm{~km}$ instead of at 55-65 km in lidar analysis. Similarly, in lidar observations the beginning of the night is warmer than the end of night in the height range of $30-40 \mathrm{~km}$; again this is in good agreement with LMDz with warm early night and cold late night in the height range of $35-45 \mathrm{~km}$.

\section{Discussion and conclusions}

The study of the lidar nocturnal evolution of the middle atmospheric temperature and its comparison with satellite data
(SABER) and different models (GSWM and LMDz) have led to the following results.

Some consistent LST-related structures have been observed on lidar data, suggesting the presence of important tidal components. In particular, a warm period has been clearly identified, propagating downward from $70 \mathrm{~km}$ at 1800 LST to $55 \mathrm{~km}$ at 0500 LST. Other LST-related structures have been observed by lidar between 30 and $80 \mathrm{~km}$ altitude, consistent with some previous lidar observations at similar latitudes.

The comparison of lidar observations with the outputs of numerical models has pointed out some similarities but also some disagreements: The amplitudes predicted by GSWM and LMDz models are much smaller than those observed by lidar and SABER model. All models exhibit the propagation of a warm layer at mesospheric height region, though there is an altitude shift in models. Below this layer, the observation of cold early night and warm late night by lidar is also predicted by GSWM with $1 \mathrm{~h}$ delay, and also in SABER with 2 h delay with weak magnitudes. There are some disagreements between models and observations in the height range of 30-60 km.

One of the possible explanations for the differences between lidar observations and GSWM predictions is the presence of local/ regional effects, which can generate nonmigrating tidal modes with periods between 10 and $30 \mathrm{~h}$. Gravity waves with 12 - or/and 24-h periods may be generated in the convectively active tropical troposphere and propagate upward. It is pointed out from the literature that some of the components of nonmigrating tides are primarily generated by latent heat released in the tropical troposphere. Its dominant mechanism for excitation is thought to be nonlinear interactions between the corresponding migrating tidal components and planetary waves. GSWM is a linear model; therefore it neglects an important excitation mechanism for nonmigrating tides, so that it underestimates observed amplitudes for some tidal components. Hence current deficiencies of the GSWM are that it does not include forcing, due to nonlinear interactions between migrating tides and stationary planetary waves (Forbes, 1995; Grieger et al., 2004), thermospheric heating due to EUV solar radiation absorption on a monthly basis, or terdiurnal tides. Moreover, GSWM overestimates eddy diffusivities in some altitude regimes (Zhang et al., 2006). Furthermore, with GSWM the altitude shift observed for the layer of fast phase transition (58-63 km) is not reduced. It is clear that the structured 
layer between 60 and $70 \mathrm{~km}$ altitude is LST related. The latitudinal uncertainty in GSWM predictions is assumed to be a latitudinal structure of the higher modes that were distorted by the climatological background winds. Also some small quantitative inaccuracies would easily lead to a substantial shift of a few degrees in the latitudinal structure of the migrating and nonmigrating tides in the nodal regions.

It is now recognized, through observational analyses (e.g., Forbes, 1995; Manson et al., 2004) and modeling studies (e.g., Forbes et al., 2001; Grieger et al., 2002; Hagan and Forbes, 2003; Ward et al., 1999), that there is a whole spectrum of tides propagating from the troposphere to the MLT, that are related to longitudinal variations in the heating rates due to variations in absorbing gas concentrations, land-sea differences and their influence on latent heat release, topography and other factors. Nonlinear tide-tide interactions (Smith and Ortland, 2001) and tide-planetary wave interactions (Grieger et al., 2004) in the stratosphere and mesosphere are also known to play a key role. Recent observations of interannual variability of low-latitude MLT tides are correlated with the El Nino-Southern Oscillation (ENSO) (Gurubaran et al., 2005).

SABER climatology is based on the observations of SABER instrument on the TIMED satellite. Space-based methods, deriving tides, using the slow local time precession rate of satellite, can be biased by longer-term temperature variations that aliased with the tidal signals. The diurnal and semidiurnal tidal components are derived by Zhang et al. (2006) using a new method for extracting tides from satellite-based data that formally eliminates the aliasing due to trends in the data (zonal mean and long-period planetary waves) that can contaminate the tidal signals. Owing to the slow local time precession rate of the TIMED satellite, at least 120 days of data are required to derive the tidal fields with this method. In the current work, the methodology is applied over 120-day intervals centered on each month assuming that the tide is geophysically significant, so that the derived tides can be highly averaged representations, and this must be kept in mind when interpreting the results. However, the degree to which such aliasing is eliminated is not well known. Between 40 and $60 \mathrm{~km}$, the effects of absorption of solar radiation by ozone give rise to a diurnal temperature response that is strongly influenced by the trapped (nonpropagating or evanescent) diurnal tidal modes (Forbes and Garrett, 1979) exhibiting large latitudinal patterns. In this height region, the SABER response is not symmetric between summer and winter, with amplitudes two times larger than those provided by the GSWM model.

LMDz is a dynamical model including the feedbacks of radiatively active chemical species imposed via climatologies. The physical parameterizations used in the model are: the radiation scheme that is based on the ECMWF scheme, the convection scheme, and the turbulent mixing in the planetary boundary layer that is based on a local second order closure formalism. It uses a Doppler spread non-orographic gravity waves drag parameterization and a subgrid-scale orography parameterization. It also includes a Rayleigh drag sponge layer above $55 \mathrm{~km}$ that probably damps the resolved waves and not the mean flow. The model uses the simulated $\mathrm{O}_{3}$ and $\mathrm{H}_{2} \mathrm{O}$ fields, greenhouse gases (GHGs) and halocarbons in their radiation calculations. Inaccuracies or differences in dynamics and transport affect water vapor and ozone distributions as described in Morel et al. (2004). For CCM, mean atmospheric field is very close to the climatology; however, the atmospheric variability is quite large (Eyring et al., 2006) and may impact tide variability.

The above observational results suggest a strong tidal effect with a descending phase (and a vertical wavelength of roughly $25 \mathrm{~km}$ ) leading to warm and cold temperature bands. More investigations based on both observation and modeling are needed to give a more detailed explanation of the differences observed between lidar and models. However, more tidal successive campaigns with full night of lidar measurements along with day time measurements will be required, as those performed sporadically at the Observatory of Haute Provence (Gille et al., 1991). However a larger coordinated campaign with more lidar sites will be required.

\section{Acknowledgements}

Long lidar data were obtained during the tidal campaigns coordinated by W. Ward in the framework of the CAWSES project while the instrument is deployed in the frame of the Network of the Detection of Atmospheric Composition Changes. Operations were funded by the Institut National des Sciences de l'Univers and the Reunion Island regional district. We acknowledge the support of the European Commission through GEOmon Integrated Project under the 6th Framework Program (Contract no. FP6-2005Global-4-036677) and the LEFFE-CHAT CNRS program. We would like to thank Prof. J.M. Forbes for providing SABER data and Prof. M.A. Hagan for providing GSWM outputs.

\section{References}

Andrews, D.G., Holton, J.R., Leovy, C.B., 1987. Middle Atmosphere Dynamics. Academic Press 489 pp.

Austin, J., Butchart, N., 2003. Coupled chemistry-climate model simulation for the period 1980-2020: ozone depletion and the start of ozone recovery. Q. J. R. Meteorol. Soc. 129, 3225-3249.

Baray, J.-L., Leveau, J., Baldy, J., Jouzel, P., Keckhut, G., Bergametti, G., Ancellet, H., Bencherif, B., Cadet, M., Carleer, C., David, M., De Mazière, D., Faduilhe, S., Godin Beekmann, P., Goloub, F., Goutail, J.M., Metzger, B., Morel, J.P., Pommereau, J., Porteneuve, T., Portafaix, F., Posny, L., Robert, M., Van Roozendael, M., 2006. An instrumented station for the survey of ozone and climate change in the southern tropics. J. Environ. Monit. 8, 1020-1028. doi:10.1039/b607762e.

Butchart, N., Austin, J., 1998. Middle atmosphere climatologies from the troposphere-stratosphere configuration of the UKMO's unified model. J. Atmos. Sci. 55, 2782-2809.

Chapman, S., Lindzen, R.S., 1970. Atmospheric Tides. D. Reidel Publishers, Hingham, MA.

Dao, P.D., Farley, R., Tao, X., Gardner, C.S., 1995. Lidar observations of the temperature profile between 25 and $103 \mathrm{~km}$ : evidence of strong tidal perturbation. Geophys. Res. Lett. 22, 2825-2828.

Dudhia, A., Smith, S.E., Wood, A.R., Taylor, F.W., 1993. Diurnal and semi-diurnal temperature variability of the middle atmosphere, as observed by ISAMS Geophys. Res. Lett. 20, 1251-1254.

Egorova, T., Rozanov, E., Zubov, V., Manzini, E., Schmutz, W., Peter, T., 2005. Chemistry-climate model SOCOL: a validation of the presentday climatology. Atmos. Chem. Phys. 5, 1557-1576.

Eyring, V., Butchart, N., et al., 2006. Assessment of temperature, trace species, and ozone in chemistry-climate model simulations of the recent past. J. Geophys. Res. 111, 22308.

Forbes, J.M., Garrett, H.B., 1979. Thermal excitation of atmospheric tides due to isolation absorption by $\mathrm{O}_{3}$ and $\mathrm{H}_{2} \mathrm{O}$. Geophys. Res. Lett. 5, 1013-1016.

Forbes, J.M., 1982. Atmospheric tides. Part 1. Model description and results for the solar diurnal component. J. Geophys. Res. 87, 5222-5240.

Forbes, J.M., 1995. Tidal and planetary waves, in The Upper Mesosphere and Lower Thermosphere: a review of experiment and theory. Geophys. Monogr. Set 87, 67-87.

Forbes, J.M., Zhang, X., Hagan, M.E., 2001. Simulations of diurnal tides due to tropospheric heating from the NCEP/NCAR Reanalysis Project. Geophys. Res. Lett. 28, 3851-3854.

Gille, S.T., Hauchecorne, A., Chanin, M.L., 1991. Semidiurnal and diurnal tidal effects in the middle atmosphere as seen by Rayleigh lidar. J. Geophys. Res. 96, 7579-7587.

Grieger, N., Volodin, E.M., et al., 2002. General circulation model results on migrating and nonmigrating tides in the mesosphere and lower thermosphere: Part I. Comparison with observations. J. Atmos. Sol. Terr. Phys. 64, 897-911.

Grieger, N., Schmitz, G., Achatz, U., 2004. The dependence of nonmigrating diurnal tide in the mesosphere and lower thermosphere on stationary planetary waves. J. Atmos. Sol. Terr. Phys. 66, 733-754.

Groves, G.V., 1982. Hough components of water vapor heating. J. Atmos. Terr. Phys. 44, 281-290.

Gurubaran, S., Rajaram, R., Nakamura, T., Tsuda, T., 2005. Interannual variabilities of diurnal tide in the tropical mesopause region: a signature of the El 
Nino-Southern Oscillation (ENSO). Geophys. Res. Lett. 32, L13805 doi:10.1029/2005GL022928.

Haefele, A., Hocke, K., Kämpfer, N., Keckhut, P., Marchand, M., Bekki, S., Morel, B. Egorova, T., Rozanov, E., 2008. Diurnal changes in middle atmospheric $\mathrm{H}_{2} \mathrm{O}$ and $\mathrm{O}_{3}$ : observations in the Alpine region and climate models. J. Geophys. Res. 113, D17303. doi:10.1029/2008JD009892.

Hagan, M.E., Forbes, J.M., Vial, V., 1995. On modeling migrating solar tides. Geophys. Res. Lett. 22, 893-896.

Hagan, M.E., Burrage, M.D., Forbes, J.M., Hackney, J., Randel, W.J., Zhang, X., 1999 GSWM-98: results for migrating solar tides. J. Geophys. Res. 104, 6813-6827.

Hagan, M.E., Forbes, J.M., 2003. Migrating and nonmigrating semidiurnal tides in the middle and upper atmosphere excited by tropospheric latent heat release. J. Geophys. Res. 108 (A2), 1062. doi:10.1029/2002JA009466.

Hamilton, K., Wilson, R.J., Mahlman, J.D., Umscheid, L.F., 1995. Climatology of the SKYHI troposphere-stratosphere-meseophere general circulation model. J. Atmos. Sci. 52, 5-43.

Hamilton, K., 1995. Interannual variability in the Northern Hemisphere winter middle atmosphere in control and perturbed experimentes with the GFDL SKYHI general circulation model. J. Atmos. Sci. 52, 44-60.

Hauchecorne, A., Chanin, M.L., 1980. Density and temperature profiles obtained by lidar between 35 and $70 \mathrm{~km}$. Geophys. Res. Lett. 7, 565-568.

Hauchecorne, A., Maillard, A., 1990. A 2-D dynamical model of mesospheric temperature inversions in winter. Geophys. Res. Lett. 17, 2197-2200.

Hedin, A.E., 1991. Extension of the MSIS thermosphere model into the middle and lower atmosphere. J. Geophys. Res. 96, 1159-1172.

Hitchman, M.H., Leovy, C.B., 1985. Diurnal tide in the equatorial middle atmosphere as seen in LIMS temperature. J. Atmos. Sci. 42, 557-561.

Hoxit, L.R., Henry, R.M., 1973. Diurnal and annual temperature variations in the $30-60 \mathrm{~km}$ region as indicated by statistical analysis of rocketsonde data. J. Atmos. Sci. 30, 922-933.

Jekins, G.M., Watts, D.G., 1969. Spectral Analysis and Its Applications. Holden Day, Oakland, California.

Keckhut, P., Hauchecorne, A., Chanin, M.L., 1993. A critical review of the database acquired for the long-term surveillance of the middle atmosphere by the French Rayleigh lidars. J. Atmos. Oceanic Technol. 10, 850-867.

Keckhut, P., Gelman, M.E., Wild, J.D., Tissot, F., Miller, A.J., Hauchecorne, A., Chanin M.L., Fishbein, E.J., Gille, J., Russell III, J.M., Taylor, F.W., 1996. Semi-diurnal and diurnal temperature tides (30-55 km): climatology and effect on UARS-lidar data comparisons. J. Geophys. Res. 101, 10,299-10,310.

Keckhut, P., Wild, J.D., Gelman, M.E., Miller, A.J., Hauchecorne, A., 2001. Investigations on long-term temperature changes in the upper stratosphere using lidar data and NCEP analyses. J. Geophys. Res. 106, 7937-7944.

Leblanc, T., McDermid, I.S., Ortland, D.A., 1999a. Lidar observations of the middle atmospheric thermal tides and comparison with the high resolution Doppler imager and global-scale wave model. 1. Methodology and winter observations at Table Mountain (34.4 N). J. Geophys. Res. 104 (D10), 11,917-11,929.

Leblanc, T., McDermid, I.S., Ortland, D.A., 1999b. Lidar observations of the middle atmospheric thermal tides and comparison with the high-resolution Doppler imager and global scale wave model. 2. October observations at Mauna Loa $\left(19.5^{\circ} \mathrm{N}\right)$. J. Geophys. Res. 104 (D10), 11,931-11,938.

Lott, F., Fairhead, L., Hourdin, F., Levan, P., 2005. The stratospheric version of LMDz: dynamical climatologies, arcitic oscillation, and impact on the surface climate. Clim. Dyn. 25, 851-868.
Manson, A.H., Meek, C.E., Avery, S.K., Tetenbaum, D., 1988. Comparison of mean wind and tidal fields at Saskatoon $\left(52^{\circ} \mathrm{N}, 107^{\circ} \mathrm{W}\right)$ and Poker Flat $\left(65^{\circ} \mathrm{N}, 147^{\circ} \mathrm{W}\right)$ during1983/1984. Phys. Scr. 37, 169-177.

Manson, A.H., Meek, C., Hagan, M.E., Zhang, X., Luo, Y., 2004. Global distributions of diurnal and semidiurnal tides: observations from HRDI-UARS of the MLT region and comparisons with GSWM-02 (migrating, nonmigrating components). Ann. Geophys. 22, 1529-1548

Meriwether, J.W., Gao, X., Wickwar, V.B., Wilkerson, T., Beissner, K., Collins, S., Hagan, M.E., 1998. Observed coupling of the mesosphere inversion layer to the thermal tidal structure. Geophys. Res. Lett. 25, 1479-1482.

Miyahara, S., Miyoshi, Y., 1997. Migrating and non-migrating atmospheric tides simulated by a middle atmosphere general circulation model. Adv. Space Res. 20, 1201-1207.

Mlynczack, M.G., 1997. Energetics of the mesosphere and lower thermosphere and the SABER experiment. Adv. Space Res. 20 (6), 1177-1183.

Morel, B., Bencherif, H., Keckhut, P., Baldy, S., Hauchecorne, A., 2002. Evidence of tidal perturbations in the middle atmosphere over Southern Tropics as deduced from LIDAR data analyses. J. Atmos. Sol. Terr. Phys. 64, 1979-1988.

Morel, B., Keckhut, P., Bencherif, H., Hauchecorne, A., Megie, G., Baldy, S., 2004. Investigation of the tidal variations in a 3-D dynamics-chemistrytransport model of the middle atmosphere. J. Atmos. Sol. Terr. Phys. 66, 251-265.

Oberheide, J., Gusev, O.A., 2002. Observation of migrating and nonmigrating diurnal tides in the equatorial lower termosphere. Geophys. Res. Lett. 29, 2167. doi:10.1029/2002GL016213.

Reed, R.J., 1972. Further analysis of semidiurnal tidal motions between 30 and $60 \mathrm{~km}$. Mon. Weather Rev., 579-581.

Rind, D., Scuozzo, R., Balachandran, N.K., Lacis, A., Russel, G., 1988. The GISS global climate-middle atmosphere model. Part 1: model structure and climatology. J. Atmos. Sci. 45, 329-370.

Smith, A.K., Ortland, D.A., 2001. Modeling and analysis of the structure and generation of the terdiurnal tide. J. Atmos. Sci. 58, 3116-3134.

Steinbrecht, W., Haßler, B., Brühl, C., Dameris, M., Giorgetta, M.A., Grewe, V., Manzini, E., Matthes, S., Schnadt, C., Steil, B., Winkler, P., 2006. Interannual variation patterns of total ozone and temperature in observations and model simulations. Atmos. Chem. Phys. 6, 349-374.

Strobel, D.F. 1978. Parametrization of the atmospheric heating rate from 15 to $120 \mathrm{~km}$ due to $\mathrm{O}_{2}$ and $\mathrm{O}_{3}$ absorption of solar radiation. J. Geophys. Res. 83, 6225-6230.

Tsuda, T., Kato, S., Manson, A.H., Meek, C.E., 1988. Characteristics of semi diurnal tides observed by the Kyoto meteor radar and Saskatoon medium frequency radar. J. Geophys. Res. 93, 7027-7036

Vincent, R.A., Tsuda, T., Kato, S., 1988. A comparative study of mesospheric solar tides observed at Adelaide and Kyoto. J. Geophys. Res. 93, 699-708.

Volodin, E.M., Schmitz, G., 2001. A troposphere-stratosphere-mesosphere general circulation model with parameterization of gravity waves: climatology and sensitivity studies. Tellus 53A, 300-316.

Ward, W.E., Oberheide, J., Riese, M., Preusse, P., Offermann, D., 1999. Tidal signatures in temperature data from CRISTA 1 mission. J. Geophys. Res. 104, $16,391-16,403$.

Zhang, X., Forbes, J.M., Hagan, M.E., Russel III, J.M., Palo, S.E., Mertens, C.J., Mlynczak, M.G., 2006. Monthly tidal temperatures 20-120 km from TIMED/ SABER. J. Geophys. Res. 111 (A10S08), 1-20. 